\title{
THE MATING BEHAVIOR OF GROMPHADORHINA PORTENTOSA (SCHAUM) (BLATTARIA, BLABEROIDEA, BLABERIDAE, OXYHALOINAE) : AN ANOMALOUS PATTERN FOR A COCKROACH ${ }^{1}$
}

\author{
By Robert H. Barth, Jr. ${ }^{2}$ \\ Department of Zoology \\ The University of Texas at Austin
}

This communication is the fourth in a series of largely descriptive papers dealing with the mating behavior of cockroaches. (see Barth, 1961; Barth, 1964; Roth and Barth, 1967; and Barth, ms in preparation). The aim of this series is twofold: first to provide background information for experimental studies, and second to provide the detailed comparative information necessary for a study of the evolution of mating behavior within the Blattaria. A more general introduction to the series may be found in Barth (1964). The anomalous mating behavior of the Madagascar cockroach, Gromphadorhina portentosa, (Schaum) forms the subject of this communication.

\section{MATERIALS AND METHODS}

Stock cultures of $G$. portentosa were maintained as described by Barth (1964) for Byrsotria fumigata. The observations on mating behavior were made in the evening (the normal active period for these animals) under red illumination is specially designed observation chambers (for details, see Barth, 1964). The ethological terms employed in the description of the behavior patterns have been previously defined by Barth (1964).

\section{RESULTS AND CONCLUSIONS}

Gromphadorhina portentosa is a large, heavy-bodied wingless species found under debris on forest floors in Madagascar (see Plate 6

\footnotetext{
${ }^{1}$ No. 4 in a series of papers entitled "The Mating Behavior of Cockroaches".

${ }^{2}$ Much of this work was carried out at the Biological Laboratiories, Harvard University. Financial support from National Science Foundation Predoctoral Fellowships and N.S.F. Grant G 19962 is gratefully acknowledged.
}

Manuscript received by the editor 5 April, 1968 
in Roth and Willis, 1960). There is considerable size variation in the adults of this species, large males sometimes reaching a length of 8 to $10 \mathrm{~cm}$. Males tend to be larger than females and differ from females in having antennae with many long laterally projecting sensory hairs, while the latter possess the simple filiform type of antennae characteristic of cockroaches. Males also differ from females in that their pronotal shields are greatly thickened and provided with a pair of large heavy knobs.

\section{Alarm Behavior and Aggressive Behavior of Males.}

The most notable features of the general behavior of this species are the aggressive behavior of the males and the production, by expulsion of air through the second pair of abdominal spiracles, of a loud hissing noise when alarmed. The former is briefly described below. Two males approaching each other while foraging, raise their bodies considerably off the substratum, curving their abdomens upwards at the tip. The rate of antennal waving or twitching increases markedly. When the antennae of the two come into contact they are twitched back and forth very rapidly and vigorously. Both animals then lower their foreparts so that their pronotal shields are directed towards the opponent. Rhythmic hissing may occur at this stage. Then they charge, their knobbed pronotal shields coming together frequently with an audible sound. They vigorously push each other back and forth, the winner being the one which can push his opponent backwards until it takes flight. Sometimes the victor slaps his abdomen vigorously against the substratum, and may turn and slap his abdomen against the opponent. A retreating animal may be vigorously chased for some distance by the victorous animal. The largest male of a group of males is the most frequent victor in these disputes and there is some evidence (Engelmann, pers. com.,) that dominance hierarchies among caged animals are set up in this way.

Dumortier (1965) discusses the hissing behavior of a closely related species, G. brunneri, and describes in some detail the mechanism of sound production. He reports that in addition to its role in alarm behavior, males of $G$. brunneri also employ hissing in aggressive behavior. According to Dumortier the aggressive behavior of $G$. brunneri males (which seems to be very similar to that of $G$. portentosa males), appears in connection with territorial defense. Mating Behavior.

There appear to be no previous accounts of the mating behavior of $G$. portentosa in the literature. The present description is based 
on observations of four successful copulations plus a number of unsuccessful copulation attempts. It has not been possible to demonstrate the involvement of a volatile female sex pheromone in the courtship behavior of this species by the means employed to demonstrate such pheromones in other species (Barth, 1964, I968a). On several occasions filter papers which had lined containers of virgin females were placed in containers of isolated males. The males showed no interest whatever in these papers.

The first observed mating behavior sequence began when a female, wandering into the male side of the mating chamber shortly after the removal of the partition, accidentally bumped into a quiescent male. The two faced each other and engaged in a prolonged period of antennal fencing. This antennal fencing is slower and much less vigorous than that associated with aggressive behavior sequences between males. The female repeatedly stroked in a gentle manner the body of the male with her antennae. The male remained motionless during this period except for antennal movements. After about two minutes he became aroused and began walking around the female with his body held somewhat off the substratum and his head and thorax raised upwards (rather than downwards as in aggreessive encounters), hissing repeatedly and stroking the female's body with his antennae. Individual hisses and the intervals between them were of approximately the same duration, the frequency of hissing being slightly less than one per second. The hissing associated with courtship is much softer than that associated with aggression or alarm but the characteristic odor associated with hissing is qualitatively the same to human olfactory receptors in all three cases. The abdominal compression associated with hissing forces an extension of the abdomen exposing the intersegmental membranes. The abdomen is flicked upwards, most noticeably at the tip, with each extension movement.

After about one minute of this behavior, the male depressed his extended abdomen so that the terminal sternites were pressed against the substratum. Both animals turned somewhat so that their abdomens came into contact. The male, while maintaining abdominal contact with the female, slid the tip of his abdomen along the side of her abdomen until their tips were directly opposed. Then he attempted to make connection with the female's genitalia by backing vigorously against her, maneuvering his abdomen somewhat from side to side in order to maintain the tip to tip abdominal contact. During this backing movement, the relatively short phallomeres of the male were protruded rhythmically. Connection was achieved 
within a few seconds, and the pair remained in the opposed position throughout the period of copulation.

The activities of the first courting pair aroused the other males sufficiently so that only brief contact with a female was necessary for release of the walking and hissing activities of the male. During this period of heightened activity, a number of males walked about hissing even though not in contact with females. If such a male did contact a female he immediately attempted to copulate. Females usually fled from such males.

Observations on four successful copulations suggest that several seconds may normally be required to achieve a satisfactory genital connection. During copulation attempts, the female may be pushed forward several inches by the male's vigorous backing movements. Copulating pairs remain quiescent even though other animals may crawl over them. Males wave their antennae quite actively during copulation. Females wave theirs much less actively. In one case a copulating pair was disturbed by the observer after about 15 minutes and the female ran off dragging the male behind her as in other cockroach species, even though in this case the male was much the heavier of the two. Copulation last a remarkably short time for so large a species, no more than twenty to thirty minutes (data from three copulations). These females were found to contain spermatophores at the termination of copulation so it may be concluded that these were normal copulations.

All successful copulations were preceded by long periods of gentle mutual antennal fencing and body stroking. Thus it seems highly probable that tactile stimulation resulting from antennal contact with a female is the normal releaser of the male's courting activities in quiescent males, and that antennal fencing promotes sexual receptivity in females. No male-male courtship sequences were observed. It seems quite possible that differences in the type of tactile stimulation resulting from antennal fencing between two individuals may alone be sufficient to determine subsequent behavior. As we have seen, the vigorous antennal fencing following male-male contacts is invariably followed by aggressive behavior, whereas the more gentle antennal fencing following male-female contacts is followed by courtship behavior. The long-laterally projecting sensory hairs on the antennae of the male may indeed be tactile receptors specialized for precisely this purpose, i.e., the detection of different intensities of tactile stimulation. This hypothesis might be tested by subjecting males to various types of artificial tactile stimulation. Whether contact chemoreception plays a role in sex recognition is unknown. 
MATING BEHAVIOR of GROMPHADORHINA PORTENTOSA

९EHAVIOR

RELEASER

O' BEHAVIOR

MOTIONLESS

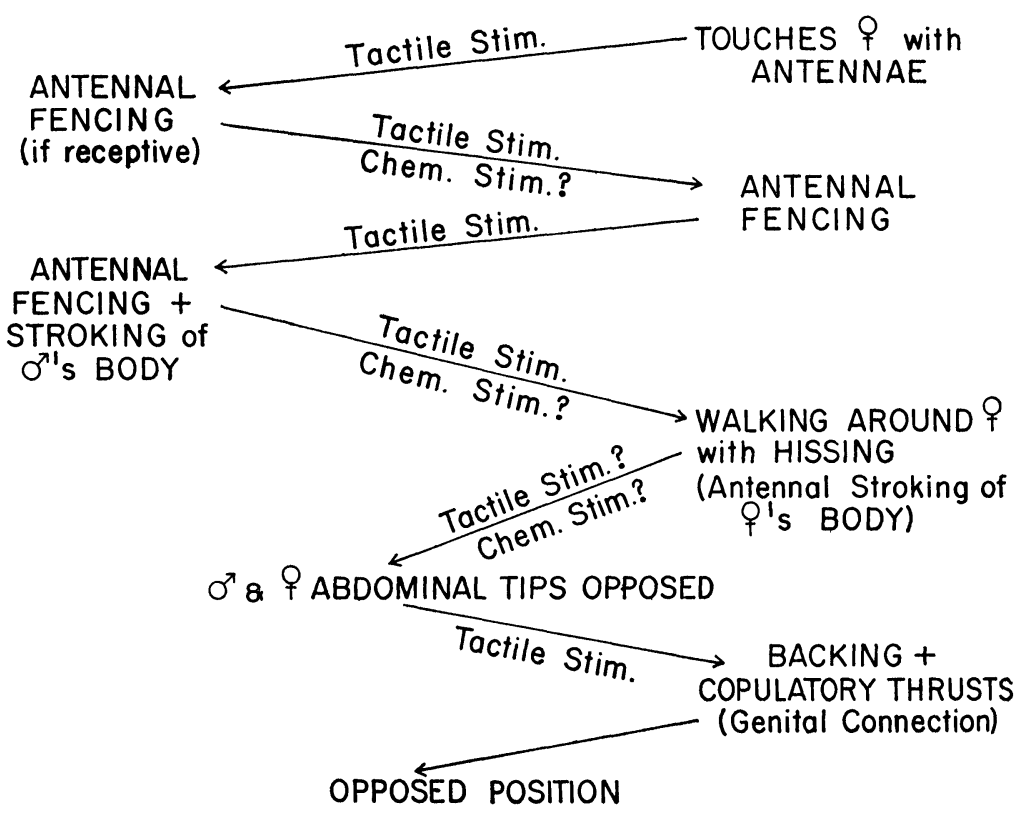

Figure 1. A summary of the mating behavior of Gromphadorhina portentosa, indicating the possible releasers for each step in the sequence.

The possible role of chemical stimuli in the release of subsequent steps in the courtship sequence is also uncertain. As noted above, there is a characteristic odor associated with the hissing male. This odor is apparent in all situations in which hissing occurs but this fact does not necessarily preclude the possibility that the odor has some effect on the level of sexual receptivity and subsequent behavior of the female, thus qualifying as a true male sex pheromone. Dumortier ( 1965 ) reports that no odor perceptable to human olfactory receptors was associated with hissing in the closely related species, G. brunneri. A schematic representation of the mating behavior of $G$. portentosa indicating the possible releasers of the various stages in the sequence is shown in Figure I. 
Dumortier (1965) reports briefly on the mating behavior of $G$. brunneri which from his description appears to be very similar to that of $G$. portentosa, and includes in sequence such elements as antennal contact, antennal fencing and mutual body stroking with the antennae, male circling the female with hissing (the individual hisses being both softer and shorter than those associated with territorial defense), and finally assumption of the opposed position by the male backing directly into the female.

The mating behavior of species of this genus represents a marked departure from the typical pattern of cockroach mating behavior as described by Barth (1961, 1964, 1968a). Variation in the male's preliminary courtship activities and in the form of the male's wing raising display (present in all winged species studied with the exception of Pycnoscelus indicus and two species of the genus Panchlora - Barth, 1968a) is frequently encountered in various phylogenetic lines of the Blattaria, but the absence of the female's mounting and feeding response is quite unusual and has been observed to occur in only three subfamilies of the Panchloroid complex of the family Blaberidae (classification according to McKittrick, 1964), the Pycnoscelinae (Pycnoscelus), the Panchlorinae (Panchlora), and the Oxyhaloinae (Gromphadorhina). In Pycnoscelus indicus, there is a reversal of the typical pattern in that the male mounts the female with very little preliminary courship (Roth and Barth, 1967). Panchlora nivea and P. irrorata resemble Gromphadorhina in that the male after a much reduced preliminary courtship achieves genital connection merely by backing into the abdominal tip of the female (Roth and Willis, I958; Willis, 1966). Within the Oxyhaloinae, mating behavior follows the typical cockroach pattern quite closely in Leucophaea maderae and Nauphoeta cinerea, the only other species which have been studied (Roth and Barth, 1967). Similarly within the Panchlorinae, the only other species for which information is available, Capucina patula, shows a fairly typical mating behavior pattern with a male wing-raising display, a female mounting and feeding response, etc. (Barth, unpublished observations). On the basis of present evidence these two subfamilies, the Oxyhaloinae and the Panchlorinae, appear to be the most interesting for study of the evolution of aberrant mating behavior patterns in the Blattaria. Investigation of additional species might reveal intermediate stages and perhaps permit some conclusion as to whether we are really dealing with the parallel evolutionary development of similar aberrant mating behavior patterns in related phylogenetic lines as currently seems to be the case. 


\section{SUMMARY}

The mating behavior of Gromphadorhina portenosa represents a marked departure from the typical pattern for cockroaches. The male recognizes the female upon contact and if the female is receptive engages her in antennal fencing and mutual stroking of the body with the antennae. Then the male proceeds to walk around the female several times hissing softly in short bursts. Finally the male orients so that his abdominal tip is opposed to that of the female and achieves genital connection merely by backing into the female. Thus the opposed copulatory position is assumed directly without the preliminary maneuvering observed in most species of cockroaches.

Also included in this communication are some observations on alarm behavior and aggressive behavior both of which also employ the curious hissing (produced by the expulsion of air through the second abdominal spiracle) noted in connection with courtship behavior.

\section{REFERENCES}

Barth, Robert H., JR.

1961. Comparative and Experimental Studies on Mating Behavior in Cockroaches, Ph.D. Thesis, Harvard University, Cambridge, Massachusetts. 274 pages.

1964. The Mating Behavior of Byrsotria fumigata (Guérin) (Blattidae, Blaberinae). Behaviour 23: 1-30.

1968a The comparative physiology of reproductive processes in cockroaches. Part I. Mating behavior and its endocrine control. Advances in Reproductive Physiology 3 : in press.

1968b. The mating behavior of Periplaneta americana (Linnaeus) and Blatta orientalis Linnaeus (Blattaria, Blattoidea, Blattidae, Blattinae) with notes on the mating behavior of three additional species of Periplaneta. Manuscript in preparation.

DUMORTIER, BERNARD

1965. L'Emission sonore dans le genre Gromphadorhina Brunner (Blattodea, Perisphaeriidae) Etude morphologique et biologique. Bull. Soc. Zool. France 90: 89-101.

McKitTrick, F. A.

1964. Evolutionary Studies of Cockroaches. Cornell Univ. Agric. Exp. Station Memoire 389, 197 pp.

Roth, Louis M. and R. H. Barth, JR.

1967. The sense organs employed by cockroaches in mating behavior. Behaviour 28: 58-94. 
Roth, Louis M. ANd E. R. Willis

1958. The biology of Panchlora nivea with observations on the eggs of other Blattaria. Trans. Am. Ent Soc. 83 : 195-207.

1960. The Biotic Associations of Cockroaches. Smithson. Misc. Coll. 141, $470 \mathrm{pp}$.

WILLIS, E. R.

1966. Biology and behavior of Panchlora irrorata, a cockroach adventive on bananas (Blattaria; Blaberidae). Ann. Ent. Soc. Amer. 59: 514-516. 

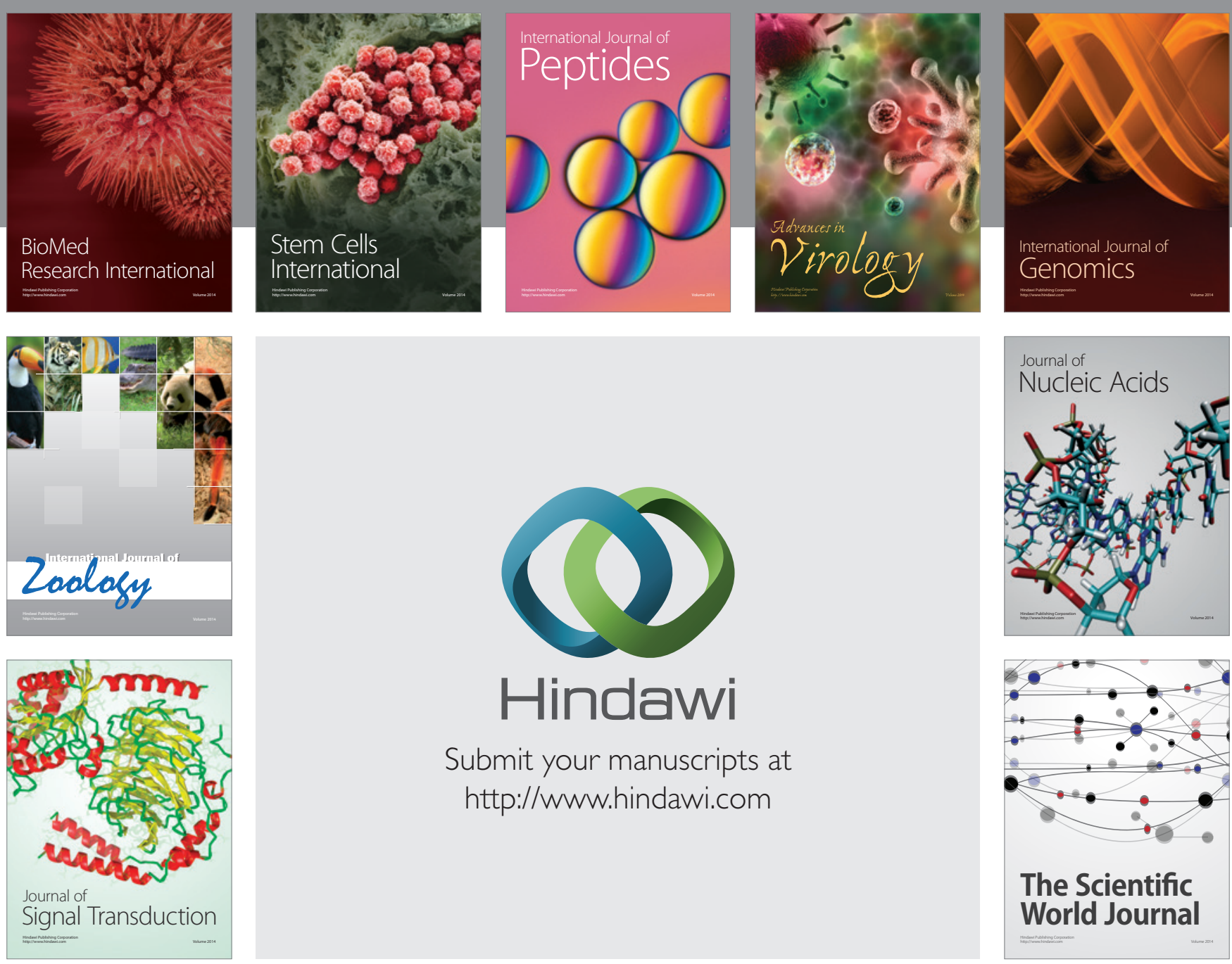

Submit your manuscripts at

http://www.hindawi.com
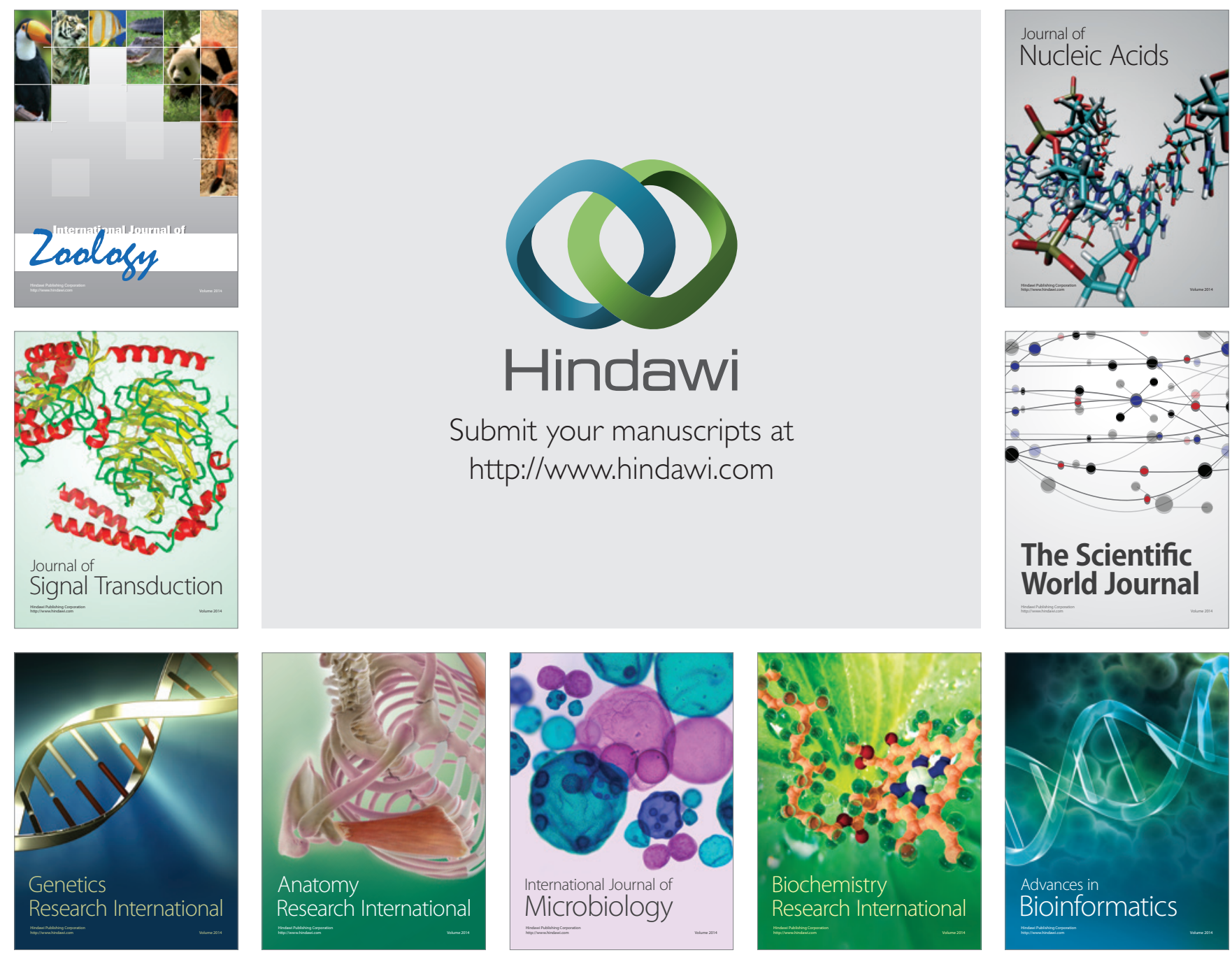

The Scientific World Journal
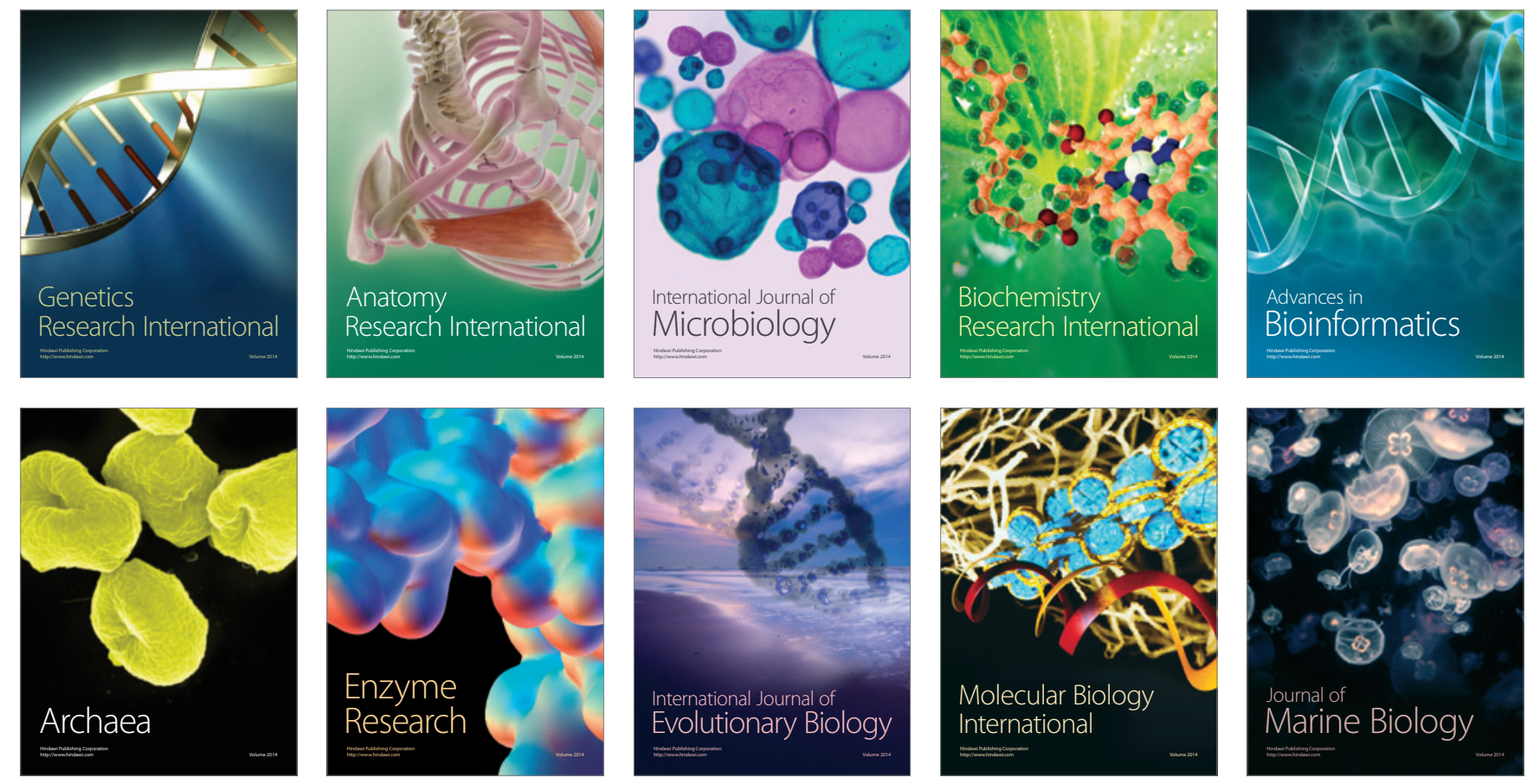